\title{
Oxygen therapy and palliative care in patients with heart failure. Response
}

Oxigenoterapia y cuidados paliativos en pacientes con insuficiencia cardiaca. Respuesta

García-Pinilla, J.M. ${ }^{\mathrm{a}, \mathrm{b}}$, Díez-Villanueva, P. ${ }^{\mathrm{c}}$, Crespo Leiro, M.G. b,d, BonanadLozano, C.

a Servicio de Cardiología, Hospital Universitario Virgen de la Victoria, IBIMA, Málaga, Spain

$b$ Centro de Investigación Biomédica en Red de Enfermedades Cardiovasculares (CIBERCV), Instituto de Salud Carlos III, Madrid, Spain

c Servicio de Cardiología, Hospital Universitario de la Princesa, Madrid, Spain

\section{To the Editor,}

We are grateful to Carratala' et al.1 for their response to our article. We fully agree with their comments on the palliative care of heart failure patients, although it is important to note that the studies they highlight essentially relate to patients with acute decompensated heart failure. The study by Rochwerg et al.2 centers exclusively on noninvasive ventilation of patients with acute respiratory failure, while the study by Tinelli et al.3 is a meta-analysis including 775 acute respiratory failure patients treated in the emergency department. The Tinelli et al. study compared noninvasive ventilation, high flow nasal cannula oxygen with conventional oxygen therapy and found no benefit of high flow nasal cannula oxygen over the other treatments in relation to the need for intubation, treatment failure, hospitalization, and mortality; moreover, the best-tolerated treatment was conven-tional oxygen therapy. 
There are also other factors that should be considered. Our consensus document is the first to address palliative care in heart failure in Spain. Palliative care is considered an essential component of the treatment of heart failure patients, 1 yet it is not prioritized in Spain, where its use in this context is largely tokenistic, especially when contrasted with the extensive access to palliative care provided to cancer patients.4 Our document has a general focus and does not go into the specific details of each treatment option for heart failure patients in palliative care. Instead, we establish general care guidelines and emphasize the need to consider and implement them early and progressively in the care of these patients. We are aware that the preparation of a more exhaustive document would probably require a dedicated supplement involving other scientific societies, in order to include input from all stakeholders with an interest in the development of consensus protocols for the treatment of heart failure patients.

\section{References}

1. García Pinilla JM, Díez-Villanueva P, Bover Freire R, et al. Documento de consenso y recomendaciones sobre cuidados paliativos en insuficiencia cardiaca de las Secciones de Insuficiencia Cardiaca y Cardiología Geriátrica de la Sociedad Española de Cardiología. Rev Esp Cardiol. 2020;73:69-77.

2. Rochwerg B, Brochard L, Elliott MW, et al. Official ERS/ATS clinical practice guidelines: noninvasive ventilation for acute respiratory failure. Eur Respir J. 2017;50. pii: 1602426.

3. Tinelli V, Cabrini L, Fominskiy E, Franchini S, Ferrante L, Ball L. High flow nasal cannula oxygen vs. conventional oxygen therapy and noninvasive ventilation in emergency department patients: a systematic review and meta-analysis. J Emerg Med. 2019;57:322-328.

4. Gastelurrutia P, Zamora E, Domingo M, Ruiz S, González-Costello J, Gomez-Batiste X. Necesidad de cuidados paliativos en insuficiencia cardiaca: estudio multicéntrico utilizando el cuestionario NECPAL. Rev Esp Cardiol. 2019;72:870-873. 